\title{
PROBLEMS ENCOUNTERED BY THE CARE GIVERS OF LOWER LIMB FRACTURED PATIENTS. "A PILOT STUDY"
}

\author{
Ms. Kammu Verma* | Dr. Krishna Chauhan ${ }^{* *}$ \\ *Ph. D Scholar, Himalyan University, Arunachal Pradesh, India. \\ **Principal, Shimla Nursing College Annadale, Shimla, Himachal Pradesh, India. \\ DOI: http://doi.org/10.47211/tg.2020.v07iws01.001 \\ Received $10^{\text {th }}$ June 2020, Accepted $16^{\text {th }}$ June 2020, Available online $30^{\text {th }}$ June 2020.
}

\begin{abstract}
:
Fracture is a break or discontinuity in the bone. Fractures are mostly the result of accidents and falls. A caregiver (sometimes called an informal caregiver) is one who cares for and gives unpaid support to a family member, friend or neighbour who is ill or disabled. The family caregiver works with the health care team and has an important role in improving the patient's health and quality of life. Caregivers of such fracture patients face many problems while providing caring like-Physical problems i.e. back pain, fatigue, and sleep disorders etc. Emotional problems are especially anxiety, frustration, anger, sadness. Financial problems are like additional expenses encountered for medications, diet, medical supplies etc. Social problems like social isolation and loneliness.

The objective of the study were to assess the problems encountered by the caregivers of lower limb fractured patients and find out the association between problems encountered by the caregivers of the lower limb fractured patients with socio demographic variables. Total study subjects were 30 at Brooklyn Himalaya hospital Baddi, Solan Himachal Pradesh. An exploratory research design was used. The data obtained was complied, tabulated and analyzed by using descriptive statistics. The study result found that overall percentage of caregiver problems was severe (73\%) while for moderate problems (27\%), and none of them had minimal problems. The result shows that the association between problems encountered by the caregivers of lower limb fractured patients with socio demographic variables. The chi-square value shows that there is significant association between the score level and demographic variables, the length of hospital stay during care giving and residential area and there is no significant association between level of score and other demographic variables.
\end{abstract}

KEYWORDS: Caregivers, lower limb fracture, problems encountered.

\section{ABOUT AUTHORS}

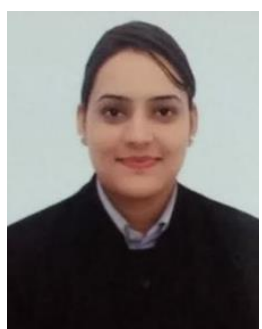

Author Ms. Kammu Verma is Ph. D. Scholar in Himalayan University, Arunachal Pradesh, India. She is working as Lecturer in Rattan Professional Education College, Sohana, Mohali, Punjab, India.

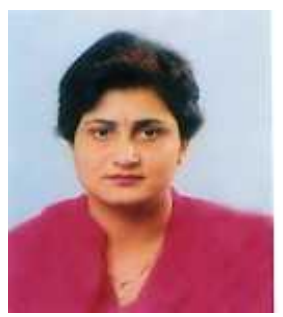

Author Dr. Krishna Chauhan is Principal in Shimla Nursing College, Annadale, Shimla, Himachal Pradesh, India. 


\section{INTRODUCTION:}

The problems with system, isn't existence threatening but they need vital impact on one's traditional activity and productivity. Bone gives shape and support to the body. The hip bones controls and endure truly weight whereas strolling or participating in numerous activities. Any separation inside the bones especially femurs deformity can create oldsters to depend upon specific people for his or her routine activities, bodily care and then on. One which suffers from lower limb fracture studied excessive pain and disability to transport his element via manner of himself or herself. In the end it bring about to severe complications like deep vein occlusion, muscle weakness, shortening of limbs, impaired skin integrity, self-care deficit, tract infections, joint stiffness, compartment syndrome place unit conceivable complications once a patient is immobilized all through the remedy of a fracture ${ }^{1}$

Trauma is one among the most common reason inside fracture .Fracture of the lower limbs is one among the most common reasons for admission to hospital. Broken bones area unit painful for a diverse of reasons. The nerve endings that surround bones contain ache fibres. Fibres may want to grow to be irritated once the bones area unit damaged or contusion. Fractures can also be of many anatomical types regular with the severity of the harm and additionally the direction of the pressure. ${ }^{2}$

A caregiver every now and then known as an off-the-cuff caregiver) is one World Health Organization cares for and provides unpaid guide to a cherished one, friend or neighbour World Health Organization is unwell or disabled .Family relatives will supply a large kind of services to fear recipients: administering drugs and therapy, assisting with each day duties (consisting of tending, meal designing and education, and ingesting , additionally as walking, sitting down and standing up), meeting with tending providers, every day supervising and activity, coordinating treatment regimens and schedules, supporting with or handling money and body aspects of medical beneficial resource. They will furthermore deliver emotional support for handling harm. ${ }^{3}$ Caregivers face numerous problems while demanding to the patients like physical, emotional, money and social issues. The individuals of own family have an incredible role in meeting the physical desires additionally because the emotional desires of the patient. The involvement of caregivers in rendering care can facilitate to get a wonderful attitude in affected individual and to perform the self-care activities to regain his/ her conventional functioning ${ }^{4}$

\section{RESEARCH STATEMENT:}

"An exploratory Study on Problems encountered by the caregivers of lower limb fractured patients."

\section{OBJECTIVES:}

- To assess the problems encountered by the caregivers of lower limb fractured patients in orthopaedic ward at selected hospitals Himachal Pradesh.

- To find out the association between problems encountered by the caregivers of lower limb fractured patients in orthopaedic ward at selected hospitals Himachal Pradesh with socio demographic variables.

\section{OPERATIONL DEFINITION:}

- Problems-- Topics or things thought to be unwelcome or dangerous and looking to be forbidden and overcome. It includes:

- Emotional issues that refers to expressing robust emotions particularly anxiety, anger, disappointment.

- Financial issues that refers to a scenario in the course of which caregiver is financially unable to worry for his/her patient.

- $\quad$ Physical issues that relates to the body like fatigue, aching and sleep disorders many others.

- Social issues that refers to lack of social touch and support and knowledge feelings of social isolation.

- Caregivers: Caregivers may be the domestic partner, sibling, parents, child, friends or any other near blood relative of age "18 years who will assist the lower limb fracture patients in activities of daily living during hospital stay and home. 


\section{MATERIAL AND METHODS:}

An exploratory research design was used to assess the problems encountered by the caregivers of lower limb fractured patients. Samples were selected by purposive sampling technique.

\section{SAMPLING CRITERIA :}

INCLUSION CRITERIA

- The caregivers of lower limb fractured patients.

- Caregivers people who will communicate in Hindi or English.

- Caregivers of patients with lower limb fractured willing to participate in analysis work.

- Respondents of patients with lower limb fractured who are available at the time of information assortment.

\section{EXCLUSION CRITERIA}

The study excludes:

- Caregivers of patients with lower limb fractured patients who were below 18 years of age would not be included.

- Caregivers who are unit health team members, paid nurses would not be enclosed.

- The participants who aren't willing to take part in the study.

\section{DESCRIPTION OF THE TOOL:}

Self-administered tool was used:

Section A: Socio demographic information: This section consists of variables to collect identification and socio demographic information such as age, gender, marital status, educational status, occupational status, monthly income, religion, residential area, relationship to the patients, types of family, dietary pattern, length of hospital stay for care giving.

Section B: Self-administered interview schedule by using likert scale on physical, emotional, financial, social problems:

This section includes questions related to problems encountered by the caregivers of lower limb fractured patients.

\section{RESULTS:}

The data was analyzed by descriptive and inferential statistical methods. The result showed the problems encountered by the caregivers of lower limb fractured patients, (73\%) had severe problems, $(27 \%)$ had moderate problems, and none of them had mild problems.

Table No.1. Table Showing Level of Scores

\begin{tabular}{|c|c|c|}
\hline \multicolumn{2}{|c|}{ CRITERIA MEASURE OF CAREGIVERS PROBLEM SCORE } \\
\hline Category Score & Percentage & Frequency \\
\hline SEVERE(113-168) & $73 \%$ & 22 \\
\hline MODERATE(57-112) & $27 \%$ & 8 \\
\hline MILD(0-56) & $0 \%$ & 0 \\
\hline & & \\
\hline
\end{tabular}

Maximum Score $=168$ Minimum Score $=0$ 


\section{ARTICLES}

Figure No. 1: diagram shows level of scores.

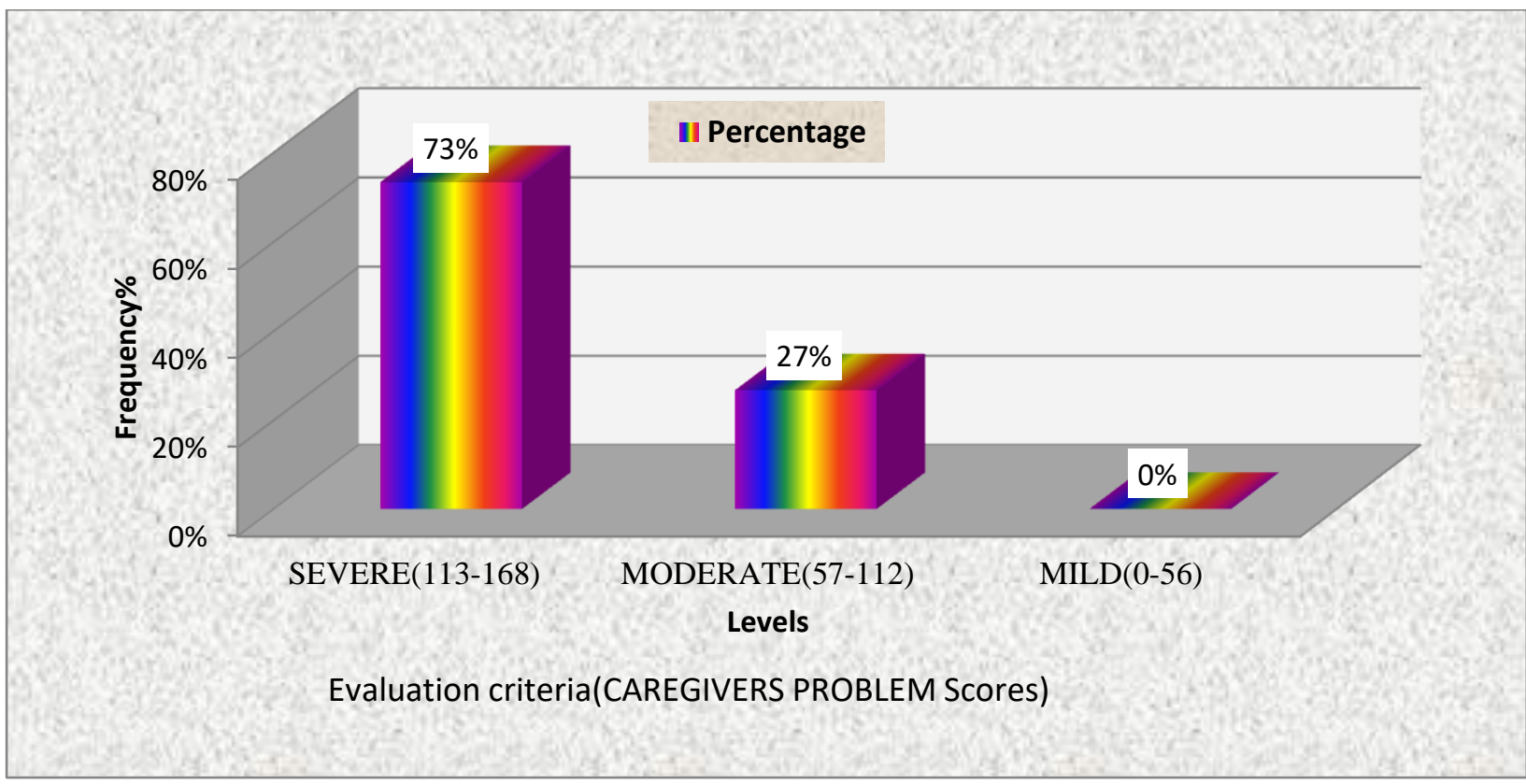

- The result shows that the association between problems encountered by the caregivers of lower limb fractured patients with socio demographic variables. The chi-square value shows that there is significant association between the score level and demographic variables, the length of hospital stay during care giving and residential area and there is no significant association between level of score and other demographic variables. And the ' $r$ ' value is 0.72 .

\section{CONCLUSION:}

The present study was conducted to assess the problems encountered by the caregivers of lower limb fractured patients. It was conducted at Brooklyn Himalaya hospital Baddi, Solan Himachal Pradesh. The objective of the study were to assess the problems encountered by the caregivers of lower limb fractured patients and find out the association between problems encountered by the caregivers of the lower limb fractured patients with socio demographic variables. The subjects of the study were 30 caregivers of lower limb fractured patients. The interview schedule was used for data collection to know physical, emotional, social, financial problems. The study result found that overall percentage of caregiver problems was severe (73\%) while for moderate problems (27\%), and none of them had minimal problems. The result shows that the association between problems encountered by the caregivers of lower limb fractured patients with socio demographic variables. The chi-square value shows that there is significant association between the score level and demographic variables, the length of hospital stay during care giving and residential area and there is no significant association between level of score and other demographic variables. 


\section{ARTICLES}

\section{REFERENCES:}

1) Aggarwal S, Bhagwat A, Dadstur FD, Patil S. Incidence of hip fractures in Indian patients. Indian J of orthop 2003 Apr;37(2):92-102

2) Chugh SN. Textbook of medical surgical nursing. $1^{\text {st }}$ edition. New Delhi: Avichal; 2013:67-88

3) Susan C. Rein hard, Carol Levine \& Sarah Samis: "Home Alone Family Caregivers providing complex Chronic Care." United Hospital Fund (search online). 2012 Available from: URL: http://www.aarp.org/home-family/caregiving/info

4) Family Caregiver Alliance: National Centre on Care giving for families (Serial online). 2005. Available from : URL: : http://www.caregiver.org/caregiver/jsp/content_node.jsp?nodeid=406 